\title{
AfROFUTURISM:
}

\section{THE World OF Black SCI-Fi and Fantasy Culture} YTASHA L. WOMACK

Chicago: Lawrence Hill Books, 2013.

ISBN: 978-1-61374-796-4 (paperback)

RRP: US \$\$16.95 (paperback)

DOI:10.12801/1947-5403.2013.05.02.08

TOBIAS C. VAN VEEN

MCGILl UNiVERSiTy (CANADA)

Following upon her accessible and personable book documenting the transformation of "race" in the late 20th century African American context, Post-Black: How a New Generation is Redefining African American Identity (2010), Ytasha Womack has written a similarly enlightening and readable survey of Afrofuturism. Womack provides several useful definitions of Afrofuturism, notably as "an intersection of imagination, technology, the future, and liberation", in which "Afrofuturists redefine culture and notions of blackness for today and the future" by combining "elements of science fiction, historical fiction, speculative fiction, fantasy, Afrocentricity, and magic realism with non-Western beliefs" (9). With its first-person narrative, easy-going interview quotes from Afrofuturist artists, musicians, writers and scholars, overview of Afrofuturism's scholarly history, artistic and musical traditions, and numerous references to past and contemporary Afrofuturist works, the book is useful for newcomers and adherents alike. Womack's chapters are prefaced by full-page black-and-white comic-style artwork from John Jennings and James Marshall, an added touch that greatly aids in visualizing the futurist hybridity of black identity and technology.

Let me not curb my enthusiasm: Ytasha Womack has successfully accomplished the longoverdue and challenging task of writing the first book-length overview of Afrofuturism. Through her concise and self-reflective reportage, Womack has explicated Afrofuturism's concepts, artists and works with ease and sophistication. She has turned to its artists and its theorists, peopling Afrofuturism with its living practitioners by conducting interviews

Dancecult: Journal of Electronic Dance Music Culture 5(2) 2013, 152-168

ISSN 1947-5403 @2013 Dancecult http://dj.dancecult.net 
and attending conferences, screenings and exhibitions. Womack has made accessible and personable the nuanced concepts of cyclic temporality and post-human identity that make up the Afrofuturist worldview. This is no easy task.

Unlike the requisite dryness of much scholarly work, Womack takes a conversational approach. Afrofuturism is viewed as a positive means to overcome barriers presented by systemic racism and socioeconomic inequality, not the least because the book is tied together by Womack's narration of her own experiences in the field - from her days discovering other "AfroGeeks" as a university student to speaking at various exhibitions and conferences as the author of the Rayla 2212 series of science fiction novels. Her reflections lend a personal aura to her ongoing encounters with all the unusual suspects of Afrofuturism.

The book's concise and digestible chapters, grouped together by approach and media format, cover all the expected bases-science fiction literature, music, comics, film, music videos, black inventors and technologies - as well as a taste of the unexpected, including the cosmogony of the Dogon, the contemporary healing practices of Malidoma Somé in Africanist religion and ritual, D. Scot Miller's Afrosurrealism manifesto, Afrofuturist curators and exhibition organisers including "The Afrofuturist Affair", and a chapter devoted to "The Divine Feminine in Space" (a.k.a. women in Afrofuturism). Womack provides a basic overview of Afrofuturist media production and its artists as well as its outliers, fielding through the Afrodiasporic speculative and science fiction of Octavia Butler, Samuel R. Delany and Nalo Hopkinson, as well as Afrofuturist musical traditions from Sun Ra and Lee "Scratch" Perry to George Clinton, Grace Jones to Erykah Badu and Janelle Monáe. In regards to speculative fiction, Womack (much to my delight) discusses African American literature of the 19th century as the forerunner to later 20th century developments, providing a summary of earlier authors including George S. Schuyler and Sutton E. Griggs while emphasizing how "the black visionaries of the past ... used [speculative and proto-science fiction] as devices to articulate their issues and visions" (124). (These earlier references, as well as Womack's passing attention to Africanist and Egyptian cosmogonies, suggest that there is still much work to be done in unearthing the deep roots of Afrofuturist approaches.)

Womack undertakes the particularly vital task of developing an inventory of Afrofuturist works that have not been covered in previous publications-a kind of minoritarian approach that balances out the erstwhile attention to the stars. She draws attention to a number of exhibits and conferences that have taken place throughout the United States featuring artists who have since picked up on the term "Afrofuturism" and utilised it to inform their work. Womack also briefly outlines "Afrofuturist critical theory" as a growing movement within scholarship to advance Afrofuturist concepts as critical tools, turning to the work of Kodwo Eshun, Alexander Weheliye, D. Denenge Akpem and Reynaldo Anderson, among others. This is where Afrofuturism offers a different sort of avenue for thought, in which Afrofuturist philosophical approaches provide a platform for discussing the concepts articulated throughout its diverse media (or implied by its practices).

In a chapter called "Project Imagination", Womack discusses the production of "futurist" 
technologies by Afrodiasporic inventors. In conversation with Alondra Nelson, Womack turns to sociological accounts of technologies invented by people of colour. This approach is particularly useful, for it demonstrates the ways in which "Afrofuturism" has been put to use to not only retroactively describe Afrodiasporic futurism but to articulate the project of reclaiming and rewriting whitewashed histories of technological production, including contemporary accounts of Afrodiasporic technological production.

C6

\section{Through her concise and self-reflective reportage, Ytasha Womack has explicated Afrofuturism's concepts, artists} and works with ease and sophistication.

Yet—and here I will turn to some suggestive criticism, which I hope the author forgives me for-while Womack lists a number of interesting technologies whose invention involved people of colour (including "the modern computer"-a claim that is perhaps more complex than she lets on, for also at stake here is an assumption of individualism over the complex collective production involved, including the role of technological actants (see Latour 2007)), her summary does not provide backgrounds of the inventors nor give detail of the inventions and their conditions of production. When turning to a book such as this, I expect most readers want to know the details, stories and struggles, including basic references of dates and places. Passing over names and details leaves black history in the shadows-a peculiar absence given the book's stated aims.

I give Womack the benefit of the doubt, however, insofar as she has crafted the text for a popular readership, and has aimed for universal breadth over microscopic depth. That said, I wish Womack had spent more time explicating various works as well as questioning her often intriguing sources. Why not? Populism shouldn't have to neglect the task of inspiring pedagogy-lessons we can draw from Freire, Fanon and Malcolm X, but also from W.E.B. Du Bois, whose The Souls of Black Folk (1994 [1903]) combined personal reflection with criticism and speculation. I would love to see Womack probe ambiguities and question stated intentions. It is evident that a number of interesting interviews lay behind this book, but for the most part they are dispersed across chapters just as they are often quoted without comment. I would also love to see longer engagements with the various artists and theorists. When she does take the time, mainly in her later chapters, Womack begins to develop her perspectives and the work of others to great effect. Perhaps we can understand this book, then, as sketching out the call signs for an Afrofuturist book to-come. 
My second criticism concerns technology, or rather Womack's approach to it. At times, she seems to equate Afrofuturism with the ideologies of Silicon Valley and its technolibertarian capitalism-what was critiqued in the 1990s on the Nettime listserv as "the California Ideology" - where new technologies are assumed to be the stepping stones to social, racial and economic liberation. A number of such quotes abound: "Today technology enables a greater ability to create and share images across the world. Social media, websites, music downloads, digital cameras, low-cost sound engineering, at-home studios, editing equipment, and on and on" (134). Womack continues in the same vein, emphasizing the spread of easy-access media production and internet distribution, before ending with "Two years ago, a still photographer shot my family reunion photo. A few months ago, a cousin shot the whole bunch (more than a hundred) with her iPad" (134). Unfortunately such wellworn celebrations" reflect an unfortunate trend of reducing radically futurist approaches to the uncritical adoption of widespread consumer communications technologies. While I do not doubt the impact of digital technology, this seems all the more reason to question it in the context of Afrofuturism (the references here are also thoroughly corporate: "iPad" and "Instragram", instead of say, "Linux" and "BitTorrent"). Is it possible to think Afrofuturism as critical of the technologies that doubtless enable it? What are the downsides to such technologies when they have just as well been used to conduct surveillance and covert operations against Afrodiasporic peoples-or people in general-agitating for change? Elsewhere, Womack performs a similar theoretical move when she equates Afrofuturology with the populist ideologies of "hope" that, for example, echoed from the campaign of President Obama. How does "hope" reconcile with a cyclical futurism in which, as Womack iterates, "the right words and actions can speak the future into existence, [just as] the same can recast the past" (153)? Part of Afrofuturism's resilience is that it avoids the wishful thinking of utopianism by inventing rituals and techniques of temporal direct action (or what Kodwo Eshun calls "chronopolitics" (2003)). Ideologies of hope appear a far cry from Eshun's militant reflections on Afrofuturism's posthuman despotism- "characterized by an extreme indifference to the human" (1999: 00[-005]) — or Sun Ra's final act of destroying Earth in Space Is the Place (1974). ${ }^{1}$

Another question lays beneath the skin of the text, as it were: the complexities behind Afrofuturist articulations of "race". Here I do not wish to criticize Womack on this point, by any account, but rather read her text as indicative of a tension within Afrofuturist scholarship. The question as to whether "Afro"-futurism is essentially tied to black bodies, or whether its imaginary force achieves an escape velocity from defining identity/ subjectivity through "racial" markers is a paradox that strikes through Afrofuturism and its scholarship, Womack included. On the one channel, Womack emphasizes the importance of black representation in science fiction, in which the "obvious absence of people of color in the fictitious future/past", and the dearth of blackness in mainstream science fiction film, television and literature provoked the imagination of "countless black kids who yearned to see themselves in warp-speed spaceships" (6) - a childhood she likewise identifies with. In her discussion of Afrofuturist scholarship, Womack places emphasis on the role 
of representation, in which scholars are apparently "dedicated to the study of works that analyze dynamics of race and culture specific to the experiences of black people through sci-fi and fantasy works" (23).

On the other channel, as Womack emphasizes, and following her similar meditations in Post-Black, Afrofuturists not only redefine contemporary as well as past/future "notions of blackness" (9), but articulate how race is "a creation too" (27). She approvingly quotes artist and filmmaker Cauleen Smith, who says "blackness is a technology. It's not real. It's a thing” (27). This approach would seem to suggest, then, that scholars should not just look for representations of blackness, "specific to the experiences of black people", but to ways in which blackness has been constructed as a particular "technolology" that Afrofuturism unearths through its alien, android and other post-human identities. At the limit is Eshun's approach that attempts to reject "all notions of a compulsory black condition" in the rendering unrecognizable of "blackness" (1999: 00[-004; -001]).

These two positions reflect a constitutive tension to Afrofuturism, one that cannot, I believe, be erased - precisely by definition of Afrofuturism. It is also what keeps Afrofuturism perpetually relevant in its transformational dialectic of cyclicity that distorts the mirror of capitalist temporality. ${ }^{2}$ Either way, this tension ought to be meditated upon explicitly, precisely as the poles of this tension can be read temporally as well as strategically: while black representation remains significant to the present, Afrofuturism dreams of a posthuman future just as it revisions the past (as Alien Nation, through time-travel, as Public Enemy's "Armageddon bin in effect", etc.). But any hint of a teleological utopianism is more complex than it appears: Afrofuturism's mission (as also articulated by filmmaker Cauleen Smith) is to invade the present with futures revisioned from the past.

What role does "race" play in the post-human, which is to say, in a future/past strategically repurposed to the present? We may turn to a sentence reflecting this tension, in which Womack notes her fascination with "the growing number of artists ... who were developing art exploring people of color and the future.... and all utilizing black characters or aesthetics to deconstruct images of the past to revisualize the future" (22). The question remains, however, as to whether blackness is to be deconstructed in the very same "revisualization" operation, and if so, what the effects are upon its sociological referents in black bodies. As Womack writes, "the notion of bending time erases the prism of race-based limitations that all too often lace the present and define the recent past" (154). But does this simply translate, as D. Denenge Akpem suggests, into "self empowerment" (154)? Or is there not a technology of self/other transformation at stake? These remain avenues of thought that, though hinted at in Afrofuturism, remain mostly unexplored. In closing, I'd like to simply emphasize that I'd love to hear Womack think through these and other questions. This hasn't been the book for it-but perhaps it is the blueprint for a book of the future.

As usual in many books published in today's market, the text is in need of some factchecking. Wallace D. Fard Muhammad, and not Elijah Muhammad, was founder of the Nation of Islam (and in 1930); Mark Sinker was a journalist at British music magazine WIRE, and not American technoculture's Wired. These are minor points, but worth considering if citing the text. 
NOTES

1 Regardless of whether it is Ra or the Overseer who destroy Earth, Ra is certainly complicit in it; these appear to be the "raised stakes" of the tarot-based cardgame, and Ra appears ultimately indifferent to its annihilation.

2 See "Vessels of Transfer: Allegories of Afrofuturism in Jeff Mills and Janelle Monáe", this issue.

\section{REFERENCES}

DuBois, W.E.B. 1994 [1903]. The Souls of Black Folk. New York: Dover.

Eshun, Kodwo. 1999. More Brilliant Than the Sun: Adventures in Sonic Fiction. London: Quartet.

- - - 2003. "Further Considerations of Afrofuturism". CR: The New Centennial Review 3(2): 287-302.

Latour, Bruno. 2007. Reassembling the Social: An Introduction to Actor-Network-Theory. Oxford: Oxford University Press.

Womack, Ytasha. 2010. Post-Black: How a New Generation is Redefining African American Identity. Chicago: Chicago Review Press.

FILMOGRAPHY

Coney, John. 1974. Space Is the Place. USA: North American Star System. < $\underline{\text { http://www.imdb.com/ }}$ title/tt0072195>. 


\section{MP3: The MEANING OF a FORMAT JONATHAN STERNE}

Durham: Duke University Press, 2012.

ISBN: 978-0-8223-5283-9 (hardcover), 979-0-8223-5287-7 (paperback)

RRP: US\$89.95 (hardcover), US\$24.95 (paperback)

DOI:10.12801/1947-5403.2013.05.02.09

\section{NABEEL ZUBERI}

UNIVERSITY OF AUCKLAND (NZ)

If history is written in a grain of sound, Jonathan Sterne turns the humble and ubiquitous MP3 inside out to reveal the longer histories of sound, music and communication embedded in the digital format. One strand of this book elaborates the importance of telephony to the development of sound technologies, a role that has often been marginalized in studies that have tended to privilege phonography and, more recently, digital media. Sterne argues that research in telephony has been central in the economic drive for compression of sound and "information" more generally. These scientific and industrial imperatives have shared many of the same ideas as intellectual fields and aesthetic movements. Sterne contends that the scientific theories and experiments that led to the MP3's emergence in the early 1990s are part of a longer process of constructing a "universal" listening subject once hearing could be isolated as a phenomenon and rationalized as an idea. The book details the pre-history and genesis of the MP3, its adoption and dissemination, its ontology and epistemology. In the process, Sterne intervenes in fundamental debates in media theory and the political economy of media and telecommunications. He engages with several key terms in audio engineering and suggests some of his own for rethinking sound and hearing. His research archive includes scientific documents, corporate histories, interviews with scientists/ engineers, and scholarship in several academic fields.

In the introductory chapter Sterne calls for "Format Theory", at once a more finely grained and more thorough and distributed approach to media and media change than the usual demarcations of film, television, radio, sound recording and digital media, for example, allow. According to Sterne, a focus on formats such as the LP, CD and cassette is more likely to reveal relations between technologies, economics and cultures of everyday practice. He proposes the concept of mediality defined as "a quality of or pertaining to media and the complex ways in which communication technologies refer to one another in form or content" (9; original italics). This ordinary cross-referencing refuses the teleologies that persist in some approaches to intermedia, remediation or transmedia, and it doesn't presume any hierarchies. Mediality provides a more contingent analysis of media and their social 
meanings, moving beyond or behind the media object to the relations between technological forms and infrastructures, codes and protocols, regulations and policies, industry standards and corporate organization. Sterne dwells on these aspects of the MP3 in part to redress the attention on MP3 players and mobile listening practices in the academic literature.

Chapter 1 addresses "Perceptual Technics" which Sterne defines as "the application of perceptual research for the purposes of economizing signals" (19). Sterne frames work at AT\&T, Bell Labs and Western Electric in early twentieth century corporations' attempts to calculate human life and apply instrumental reason to human bodies for profit. The goal of corporate monopoly fuelled research on hearing in psychoacoustics. Taking cues from Foucault on power/knowledge and Bourdieu on fields, Sterne connects the legitimization of this scientific field with its institutional context. In and through media technologies such as the audiometer, which aimed for standardized measurements, hearing was abstracted from bodies and experiences. Different kinds of value could be ascribed to particular frequencies, and some frequencies could be defined as surplus. Sterne coins the term "surplus definition" for the difference between the definition of sound that could be produced and the definition required for the signal to still work. That difference generated "perceptual capital" which could generate economic value. In this probing and measurement of the inner ear and the mind's ear, theories of sound and corporate research shaped by technologies sought efficiencies in signal transmission and reception.

Chapter 2 "Nature Builds No Telephones" proceeds with this genealogy of the MP3 into the period from the 1920s to the 1940s, as psychoacoustic research and its technologies continue to model and abstract hearing with such innovations as cochlear microphonics, and define the sense as a form of information processing. Sterne contends that this research influenced the development of information theory and cybernetics more generally during this period. This chapter centres on what now seems a bizarre and cruel experiment in 1929, in which Ernest Glen Wever and Charles W. Bray at Princeton University removed the mid brain and cerebral cortex of live cats that were wired into an AT\&T phone system. These feline cyborgs contributed to theories of signal transmission, and "perceptual coding" of audio at the "minimum threshold of intelligibility to people and machines" (84).

In Chapter 3 Sterne examines perceptual coding in the 1980s in the broader context of a "domestication of noise" on a number of fronts in the 1960s and 1970s, including the use of noise in dentistry, workplaces, and experimental and popular music. Practices in these fields inform each other with practitioners often moving between them. By the '70s, scientists had realized that they didn't need to eliminate noise but could mask annoying or unnecessary sounds with other sounds. Theories of psychoacoustic masking and models for compression of sound shaped theories and models for digital communication, and computers increasingly mediated the ways in which scientists imagined hearing. Inventions like the vocoder which synthesized speech and computer models of hearing based on the cochlea are indicative of sound culture defined by what Sterne-riffing on Jacques Attali's age of "composition" - calls "decompositionism", which he defines as a "new malleability of sound and noise across cultural domains that emerged in the 1960s and 1970s" alongside 
"processes that analyze it, decompose it, and reassemble it" (127).

Chapter 4 arrives at the MP3 proper and how the format was made an industrial standard through a series of negotiations, struggles and compromises between different economic interests in the telecommunications, broadcasting, consumer electronics and computer industries. The MP3 emerged from companies with different markets and distinctive technological requirements. Two codecs for coding and decoding audio competed for prominence, representing two consortia. On the one hand was MUSICAM, which comprised primarily of Philips and Panasonic/Matsushita, and on the other was ASPEC, supported primarily by Fraunhofer IIS (Institut für Integrierte Schaltungen/Institute for Integrated Circuits), AT\&T, Thompson, and France Télécom. MPEG (Motion Picture Experts Group), which had been formed as an extension of the JPEG (Joint Photographic Experts Group) in 1988, arbitrated competing interests and itslayer scheme for the new digital format accommodated these different constituencies. Layer 2 represented MUSICAM, but ASPEC's layer 3 compressed audio better than layer 2, though it sacrificed quality of sound. In this chapter, Sterne argues that we need to focus more on the politics and governance of audiovisual standards in studies of media regulation, since such standards are increasingly defined across several media sectors.

From this industry focus, Chapter 5 shifts to aesthetic judgments in the design and interpretation of listening tests in 1990 and 1991 that shaped the MP3 format. Far from being "objective", these tests constructed a particular type of listening subject and propagated certain values about what constituted "good sound". They aimed to remove subjective experience and context from their listening, but chose particular genres or styles of music for their listeners. While appearing disinterested, they mobilized the tastes of the engineering culture in which they were designed. Sterne recounts an anecdote about Suzanne Vega visiting the labs where her song "Tom's Diner" had been one of the key pieces of music in the testing of the MP3 standard to explain the clash in listening subjectivities between audio engineers and many other listeners.

Chapter 6 explains the success of the MP3 as a "nonrivalrous" and "nonexcludable" resource in the 1990s and 2000s due to a confluence of industrial, technological and cultural forces in which the record industry was slow to embrace Internet distribution of music, and computer manufacturers and consumer electronics led the way. The Internet Underground Music Archive, Napster, and piratical or unauthorized reproduction and distribution were elements though not determinants in the mix. Sterne uses the debates around piracy to ask if music is a thing or a process. He opts to take a middle path that conceives of it as a "bundle of affordances" and outlines the major perspectives on music as technology, commodity, property, and the idealized (romantic and modernist) work of art beyond performance. The MP3 is enmeshed in processes but as a container technology is treated as a thing. Against some of the romantic, utopian and singular positions taken up in debates around Internet music and piracy, the chapter critiques libertarian views of information and the way the notion of the gift economy has been used to understand often non-reciprocal MP3 traffic without obligations to return the gift. He also picks apart the 
music industry's rhetoric on piracy. Sterne is persuasive in his argument that the history of music piracy from radio, to home taping and the Internet in many parts of the world reveals that unsanctioned forms of copying and distribution and their associated activities have often had a symbiotic relationship with sanctioned market practices. He is skeptical about anti-copyright movements constituting a coherent public that might counter the capitalist organization of music, instead more keen to stress that capitalist and non-capitalist forms of music making and exchange have existed together for a long time. It will be interesting to see if the progress of organizations such as the Pirate Party and others advocating culture of the commons will contradict Sterne's playing down of their political possibilities.

\section{Jonathan Sterne turns the humble and ubiquitous MP3 inside out to reveal the longer histories of sound, music and communication embedded in the digital format.}

The book's conclusion speculates about both the resilience and the possible end of the MP3. As Sterne notes-and I can confirm since I happen to be typing this on the first Cassette Store day-older or residual media formats survive; though he also points to the fragility of digital files and hard drives which means that some major currents in MP3 music such as the mashup may not be archived adequately. Sterne also mentions the aesthetics that have emerged as electronic musicians and DJs have played with the MP3's sonic qualities on other software platforms. He predicts the persistence of audio compression, given the desire for music in mobile technologies such as smart-phones, and wireless communication between different technologies. More importantly, he argues that what we consider media today might be more "diluted" and distributed, so that issues around infrastructures, formats and platforms might become more significant for the politics of communication.

Sterne's book offers scholars of dance musics many entry points and applications. We already have considerable scholarship on particular formats such as the 12-inch single and cassette. Most obviously but importantly, this history of the MP3 reminds us that new or digital media are actually part of longer histories, and that the analogue vs. digital schism is overstated. There are lessons here for those studying the intersections of economic, political, social and cultural forces in which music hardware and software of various kinds emerge and become widely used and dumped. Sterne's discussion of noise is useful for thinking how what seem like disparate fields of production (science and art) are actually asking the same questions and using similar concepts. His argument doesn't assume that noise in music or sound art is necessarily radical or transgressive, but can be quite ordinary and 
accommodated in existing systems. In thinking about the "good" or "bad" sound of audio formats, we might reflect on the taste formations and values that inform these judgments and how they do or do not acknowledge and encourage a plurality of listening practices. We can trace how subcultural networks and music piracy may not fund terrorism, but might gel with regular business in many respects. There is much in this big book about a little thing that will inform scholarship across sound studies, communication and popular music studies.

DISCOGRAPHY

Vega, Suzanne. 1987. Tom's Diner. A\&M (7-inch): VEGA2. <http://www.discogs.com/ Suzanne-Vega-Toms-Diner/release/570788>.

\section{Electronica, Dance and Club Music MARK J. BUtLER (ED.)}

Farnham: Ashgate, 2012.

ISBN: 978-0-7546-2965-8 (hardcover)

RRP: $£ 170.00$ (hardcover)

DOI:10.12801/1947-5403.2013.05.02.10

\section{Hillegonda C. RietVeld}

LONDON SOUTH BANK UNIVERSITY (UK)

As part of their series The Library of Essays on Popular Music, Ashgate offers an anthology of English-language academic work on electronic dance (and) club music that has developed since the early 1990s. Added to this is Richard Dyer's 1979 trailblazing paper "In Defense of Disco", which points to the radical potential of the experience of dancing to DJ-driven music.

Compiled by musicologist Mark J. Butler, the selection of twenty-eight ready-edited contributions offers topics that go beyond rave, techno, house and trance to include kwaito, nor-tec and glitch. It opens with a useful explorative piece on digital DJ-ing by Pedro Peixoto Fereira, arguing that the DJ and dancers are part of an interactive network in which dancers actively embody the recorded music. The articles, chapters and other extracts that follow are divided into three sections: Part I, Production, Performance and Aesthetics; Part II, The Body, The Spirit and (the Regulation of) Pleasure; and Part III, Identities, Belongings and Distinctions. These include authors such as Mark J. Butler, Tara Rodgers, 
Fiona Buckland, Anthony D’Andrea, Graham St John, Arun Saldanha and others, who engage with electronic dance music cultures from musicological and/or anthropological perspectives.

In the introduction, Butler justifies the selection by defining the music cultures in this collection on the basis of four criteria. First, the music under discussion is performed by DJs and digital producers. Second, the music is produced for dancing, and thereby part of a dance culture. Third, the engagement with this music is site-specific, depending on what may be called a "club-concept" (xi). Fourth, the electronic dance music culture that is addressed here has a common history in disco and can be regarded as post-disco. In short, the common attributes here are "electronic sound production and performative consumption through dance" (xiii) - although it is also pointed out that electronica, as a music genre, is not necessarily made for dancing.

Counting 536 pages, plus preface and introduction, this is a substantial book. A complete anthology is never possible, but it does provide a handy point of reference for those that teach in the area of electronic dance music and culture, and it can also work well as a primer for an early literature review in research dissertation work. Included are many classics in the field, by authors such as Kai Fikentscher, Tim Lawrence, Barbara Bradby, Philip Tagg, Sarah Thornton, Maria Pini, Sean Albiez and Ben Malbon. These are mainly selected from academic journals, such as Popular Music, Journal of Popular Music Studies, or Culture and Religion, as well as a range of academic book publications.

However, it seems surprising that no work appears from Ashgate's own explorative publications in the field, initiated in 1993 by Rave Off: Politics and Deviance in Contemporary Youth Culture, edited by Steve Redhead for its previous subsidiary, Avebury. Neither does it offer a selection of non-academic, yet knowledgeable and reflective existing work by journalists and creative producers in the field, comparable to the approachable mix of Audio Culture: Readings in Modern Music, edited in 2004 for Continuum by Christoph Cox and Daniel Warner.

Even more surprising is the forbidding price of this anthology, currently available in hardback only, given that no original work was produced, apart from the introduction, and no copyediting was required, even maintaining the original layout of the contributions. Why does such a popular topic of study have to be so inaccessible? It seems that Ashgate has, so far, missed out here on the opportunity to reach a potentially much wider readership.

\section{REFERENCES}

Cox, Christoph and Daniel Warner, eds. 2004. Audio Culture: Readings in Modern Music. London: Continuum.

Redhead, Steve, ed. 1993. Rave Off: Politics and Deviance in Contemporary Youth Culture. Aldershot: Avebury. 


\section{ELECTRONIC AWAKENING}

\section{DIR. ANDREW JOHNER}

USA: Federation of Earth, 2011.

http://www.imdb.com/title/tt2038260/

DOI:10.12801/1947-5403.2013.05.02.11

\section{GARTH SHERIDAN}

RMIT UNIVERSITY (AU)

In the midst of the growing mainstream acceptance and corporatization of EDM cultures in North America, Electronic Awakening is a welcome glance into independent gatherings that have been ongoing since the early 1990s. Though touching on earlier events, the film focuses on the contemporary outdoor electronic dance music scene, and was shot between 2006 and 2011 at parties including Burning Man, Earthdance, Shambala and LoveFest. Alongside festival footage, the film interviews a wide range of DJs, promoters, religious figures, journalists and academics including Terrence McKenna, Robin Sylvan, Anthony D’Andrea, Graham St John and members of Moontribe, Wicked and Tribal Harmonix. The primary emphasis of the documentary is the deeply spiritual basis of the cultures and practices that have developed around these parties, particularly trance music and the possibilities this spirituality might offer for ravers and the world in general.

The interviewees suggest that for people organizing and attending these events, the raves are 21st century "tribal gatherings", where one can experience connectivity to the other ravers and the land, while experiencing states of ecstasy and participating in cleansing through collective dance. Executive producer Julian Reyes sees the experience as rooted in contemporary culture, while building upon older knowledge and belief systems, suggesting that "electronic music is modern shamanism; it is the evolution of ritualized drum circles" (Cronshey 2011). Arguably, the experience of attending raves and participating in spiritual activities potentially offers an alternative to organized religion and a more intuitive connection to divinity.

The development of America's outdoor rave scene is framed as a reaction to increasingly restrictive anti-rave legislation that pushed promoters outside of traditional club spaces, either into larger commercial dance parties, or underground to the limits of the city and into the desert. San Francisco house pioneer DJ Garth explains the motivation for the early outdoor parties thrown by Wicked Crew to be a move away from the restrictions placed on downtown clubs, and a chance to get in touch with nature with the freedom to dance on the beach at full moon. The full moon parties are considered a cornerstone of the outdoor scene in America, and led to the Wicked Tour over the summers of 1994 and 1995, which saw the group travel across America in an old bus with a sound system. This 
tour was instrumental in spreading the outdoor rave culture across America and culminated in Burning Man Festival. Director Andrew Johner returns to Burning Man throughout the film, and positions the festival as an experiment in an alternate, utopian organization of society based around community, spirituality, support and self-expression, devoid of judgment and capitalist exploitation. In this sense, Burning Man is representative of the values of the scene as a whole.

Through the interweaving of footage filmed at festivals and interviews, outdoor parties are presented as religious gatherings. Festival-goers are shown to establish spontaneous altars to a diverse range of deities, take part in handholding circles and enter altered, ecstatic states. The festival footage used in the film captures the ritualistic, spiritual nature of collective dance that participants experience. Many of those interviewed suggest that dancing to repetitive rhythms induces a state of bliss and transcendence, which opens the mind to positivity and reprogramming. Neo-pagan author Starhawk draws parallels between the outdoor party movement and Earth-based religions, in that they prioritize experience over specific belief systems or dogma. While the personal and non-prescriptive journey of festival spirituality is emphasized, moments where participants reflect on specific rituals, such as Goa Gil spreading Ganga water and building altars to prepare festival sites, ground the discussion and may be more accessible to those outside the movement.

The film presents outdoor raves as a global movement, with people all around the world organizing festivals and engaging in spiritual communion. The footage of Portugal's Boom Festival visually reflects this global dimension, however interviews with attendees and organizers could have been used to make these links explicit. For example, the interview with DJ Garth could have delved into the historical and global context of the outdoor party scene due to his background in London's acid house scene and role in developing UK-style, Jamaican-influenced sound system culture in America. Similarly, Goa Gil is a Sadhu and was predominantly based in the Indian state of Goa through the 1980s and 1990s and was a key figure in the development of Goa trance. Developing strong counter cultural and religious components, Goa trance bound the musical and spiritual together in a significant way, laying the foundation for contemporary gatherings.

Conceived as part of a larger work including the production of a book, the development of the project into other formats may provide possibilities for greater detail and a deeper, critical analysis of the varied manifestation of spirituality in electronic dance music cultures. Electronic Awakening is aimed at a wider audience than those actively participating in the outdoor trance scene, but this is where the documentary is likely to find the most resonance. Indeed, the film has been screening at outdoor parties and chill out spaces globally to great response since 2011 .

\section{REFERENCES}

Cronshey, Terra. 2011. "Dancing to the Digital Shamans". Catalyst Magazine. 30 November: $<$ http://www.catalystmagazine.net/component/k2/item/1818-dancing-to-the-digital$\underline{\text { shamans }}>$ (accessed 23 June 2013). 


\section{SHOWTIME}

\section{DiR. ROLLO JACKSON}

UK: Heatwave, 2011.

http://www.theheatwave.co.uk/

http://vimeo.com/45444078

DOI:10.12801/1947-5403.2013.05.02.12

\section{PHILIP KIRBY}

UNIVERSITY OF LIVERPOOL (UK)

Showtime is a documentary record of a dancehall based club night in London that took place in June 2011. The event was hosted by the Heatwave crew who regularly promote reggae dancehall events and also present a show on London's Rinse FM. The DVD sleeve notes explain that the event was intended to be an "explosion of UK dancehall history, bringing together legends from every era of UK rave music to share the mic and spit lyrics over classic dancehall riddims" (Jackson 2011). In common with the 2008 Soul Jazz Records release $A n$ England Story (also compiled by Heatwave) the event sets out to showcase the evolution of the UK MC from '80s UK reggae to the current generation of grime MCs. Simon Reynolds identifies a range of Jamaican musical practices that have been integrated into UK dance music from hardcore onwards in his book Energy Flash, but in this documentary the MC is the focus. A potentially confusing point for the non-aficionado is that in reggae sound system parlance MCs are called DJs. So, textual references to reggae artists that rap (or chat) will often refer to them as DJs. I'll use the term MC throughout this review.

Early UK hip-hop was often hindered by the MC's clumsy attempts at adopting an American accent, Derek B's 1988 hit "Good Groove" being one example of this phenomenon. UK MCs subsequently found their voice by incorporating influences from Jamaican culture. Jamaican street style has been influential in the UK for many years, and patois has gradually been incorporated into UK street vernacular. The integration and incorporation of Jamaican culture into British youth culture is well documented by academics such as Les Back, who has explored black music, youth culture and syncretism in the UK.

The DVD is dedicated to UK reggae artist Smiley Culture, who died in questionable circumstances in 2011. The origins of the UK MC style lie in the "fast chat" vocal style popularized by Smiley Culture and his associates. This style is considered to have originated from vocalists associated with the UK's Saxon sound system in the 1980s. There was a rapid development in the credibility of UK "urban" music once UK-based MCs looked to their (or their peers') Jamaican ancestry and started to base their style on a hybrid British/Jamaican syncretic template that was informed by dancehall reggae. MCs became 
an integral part of the UK's rave scene in the late 1980s, and this continued in the 1990s, as the MC became a key feature of jungle and drum and bass clubbing. Interestingly, this was despite drum and bass releases generally being instrumentals, or using sampled vocals, as the producer was the focal point in most drum and bass recordings. In a live scenario the sound system ethos held sway, and the interaction between the DJ, MC and the crowd was of central importance. The centrality of the live MC in a club environment continued as UK garage and its sub-styles evolved. Although grime is often seen as a form of hiphop it owes a greater cultural debt to reggae, and this film offers a useful and entertaining visual and aural lesson on the influence of Jamaican culture on the contemporary UK bass music scene. Simon Reynolds has coined the term "hardcore continuum" to explain the chronological influence of Jamaican musical practices on UK dance music: "I've argued that the hardcore continuum is a UK adaption of the Jamaican system". (Reynolds 2010: 70). This film reinforces the validity of his observations.

Showtime mainly consists of live footage mixed with short interview segments with a number of the featured MCs. The performers range from '80s UK reggae artist Asher Senator to grime MCs such as Wiley and Flow Dan. Jungle, UK garage and dancehall MCs are also featured. The backing tracks are predominantly oriented towards dancehall, although there are also grime instrumentals incorporated into the set, such as Wiley's "Ice Rink". The show incorporates sound system practices, notably numerous "rewinds", and, unlike the DJ practices of other genres, seamless multi-deck mixing isn't the objective. From the brief interview segments the centrality of sound system culture and pirate radio to the emergence of UK bass music styles becomes clear. Early in the DVD Lady Chann comments that without Smiley Culture there wouldn't be grime MCs, and Wiley also acknowledges the influence of dancehall on his own performance practice. DJs Chris Goldfinger and David Rodigan are identified as particularly influential in popularizing Jamaican music in recent years. Various interviewees acknowledge key UK sound systems like Saxon and Coxsone as having had a considerable influence on the evolution of the UK scene, as well as acknowledging pirate radio's impact. Refreshingly, female dancehall MCs are featured in the show and interviewed at some length.

Essentially, this film offers an oral history that validates many aspects of Simon Reynolds' hardcore continuum: "It's a particular set of relations based around pirate radio, dubplates, raves and rave-style clubs, along with certain kinds of music-making technology" (Reynolds 2010:70). The film also illustrates the syncretic nature of the UK bass music scene. The DVD could be useful as a teaching resource to explore syncretic culture, or to anyone interested in the various Jamaican-inflected strands of UK dance music. The film makes clear the links between reggae-influenced contemporary dance music styles and their precursors, which can be helpful when trying to explain to students the formative influences that paved the way for dubstep. A notable omission from the event's line up is that there weren't any MCs representing the UK hip-hop scene, as artists such as Blak Twang and Roots Manuva also demonstrate a clear Jamaican influence in their work. The logistics of booking the sixteen featured MCs would have been challenging enough I'm sure, without covering every possible 
base. An interesting point that can be gleaned from the audience shots on the DVD and from photographs on Heatwave's website is the demographic at the events they promote. In contrast to dancehall's "traditional" core Jamaican audience, Heatwave's audiences demonstrate a crossover into a young multicultural demographic. Coincidentally, in June 2013 UK dancehall artist Stylo G achieved a top twenty chart position demonstrating that the impact of Jamaican music on the UK's popular music landscape continues. If we consider that this process started with Millie Small's "My Boy Lollipop", this is a cultural dialogue that has lasted almost half a century.

\section{REFERENCES}

Back, Les. 1996. New Ethnicities and Urban Culture: Social Identity and Racism in the Lives of Young People. London: Routledge.

Reynolds, Simon. 1998. Energy Flash. London: Picador.

Reynolds, Simon. 2010. "The History of Our World: The Hardcore Continuum Debate". Dancecult 1(2): 69-76. <http://dj.dancecult.net/index.php/journal/article/view/47/79> (accessed 12 July 2013).

\section{DISCOGRAPHY}

Derek B. 1988. Good Groove. Music of Life (7-inch): 7 NOTE 12. $<$ http://www.discogs.com/Derek-B-Good-Groove/release/230258>.

Millie Small. 1964. My Boy Lollipop. Fontana (7-inch): 267331 TF. $<$ http://www.discogs.com/Millie-My-Boy-Lollipop/release/763685>.

Various. 2008. An England Story. Soul Jazz Records (CD COMP): SJR CD 177. $<$ http://www.discogs.com/Various-An-England-Story/release/1990379>.

Wiley Kat. 2003. Eskiboy/Ice Rink. Wiley Kat Records (12-inch): WK015. $<$ http://www.discogs.com/Wiley-Kat-Eskiboy-Ice-Rink/release/692408 $>$. 